\title{
NVP-BEZ235 and NVP-BGT226, dual phosphatidylinositol 3-kinase/mammalian target of rapamycin inhibitors, enhance tumor and endothelial cell radiosensitivity
}

Emmanouil Fokas ${ }^{1}$, Michio Yoshimura', Remko Prevo', Geoff Higgins' ${ }^{1}$, Wolfgang Hackl², Sauveur-Michel Maira², Eric J Bernhard', W Gillies McKenna ${ }^{1}$ and Ruth J Muschel ${ }^{1,3^{*}}$

\begin{abstract}
Background: The phosphatidylinositol 3-kinase (PI3K)/Akt pathway is activated in tumor cells and promotes tumor cell survival after radiation-induced DNA damage. Because the pathway may not be completely inhibited after blockade of PI3K itself, due to feedback through mammalian target of rapamycin (mTOR), more effective inhibition might be expected by targeting both PI3K and mTOR inhibition.

Materials and methods: We investigated the effect of two dual PI3K/mTOR (both mTORC1 and mTORC2) inhibitors, NVP-BEZ235 and NVP-BGT226, on SQ20B laryngeal and FaDu hypopharyngeal cancer cells characterised by EGFR overexpression, on T24 bladder tumor cell lines with H-Ras mutation and on endothelial cells. Analysis of target protein phosphorylation, clonogenic survival, number of residual $\gamma \mathrm{H} 2 \mathrm{AX}$ foci, cell cycle and apoptosis after radiation was performed in both tumor and endothelial cells. In vitro angiogenesis assays were conducted as well.

Results: Both compounds effectively inhibited phosphorylation of Akt, mTOR and S6 target proteins and reduced clonogenic survival in irradiated tumor cells. Persistence of DNA damage, as evidenced by increased number of $\gamma \mathrm{H} 2 \mathrm{AX}$ foci, was detected after irradiation in the presence of PI3K/mTOR inhibition, together with enhanced G2 cell cycle delay. Treatment with one of the inhibitors, NVP-BEZ235, also resulted in decreased clonogenicity after irradiation of tumor cells under hypoxic conditions. In addition, NVP-BEZ235 blocked VEGF- and IR-induced Akt phosphorylation and increased radiation killing in human umbilical venous endothelial cells (HUVEC) and human dermal microvascular dermal cells (HDMVC). NVP-BEZ235 inhibited VEGF-induced cell migration and capillary tube formation in vitro and enhanced the antivascular effect of irradiation. Treatment with NVP-BEZ235 moderately increased apoptosis in SQ20B and HUVEC cells but not in FaDu cells, and increased necrosis in both tumor and endothelial all cells tumor.
\end{abstract}

Conclusions: The results of this study demonstrate that PI3K/mTOR inhibitors can enhance radiation-induced killing in tumor and endothelial cells and may be of benefit when combined with radiotherapy.

Keywords: PI3K, mTOR, Radiosensitization, Endothelial cells, VEGF

\footnotetext{
* Correspondence: ruth.muschel@oncology.ox.ac.uk

1 Gray Institute for Radiation Oncology and Biology, Oxford University,

Oxford, UK

Full list of author information is available at the end of the article
} 


\section{Background}

Radiotherapy is one of the most important modalities for the management of cancer. However, despite progress in radiation technology and significant gains achieved with the use of combined radio-chemotherapy, there is a substantial proportion of patients that fail to achieve long-term control [1]. The latter provides a strong rationale for combining molecular targets with radiation to improve patient outcome.

The phosphatidylinositol 3-kinase (PI3K)/Akt/mammalian target of rapamycin (mTOR) pathway controls tumor cell proliferation, growth, and survival after DNA damage [2]. Activation of this pathway is frequent in many cancers and can occur through diverse mechanisms such as amplification of the epidermal growth factor receptor (EGFR) gene, mutations of the Ras oncogene, PI3K mutations and loss of phosphatase and tensin homologue deleted in chromosome 10 (PTEN) [1-3]. This pathway consists of EGFR/Ras/PI3K/Akt and is a prime target for inhibition in the context of radiotherapy [4-6]. We and others have previously shown that inhibition of the EGFR/Ras/PI3K/Akt pathway can increase susceptibility to radiation-induced tumor killing [3,7-11]. Inhibition of Ras, PI3 kinase and Akt reduce tumor clonogenic survival after radiation at clinically relevant doses $[3-5,7,10,12]$. A phase III randomized clinical trial evaluated the addition of cetuximab, an EGFR inhibitor, to radiotherapy and demonstrated improved overall survival in the combined modality arm over radiation alone [13].

The kinase mTOR consists of TORC1 and TORC2, two functionally distinct multiprotein complexes [14]. TORC1 includes mTOR and raptor (regulatory-associated protein of mTOR). TORC2 is composed of mTOR and rictor (rapamycin-insensitive companion of TOR) and regulates the activity of Akt [14]. mTOR inhibitors have radiosensitising potential in tumor and vascular cells $[15,16]$. Inhibition of TORC1 activity alone can result in TORC2-mediated feedback phosphorylation of Akt on Ser473 [14,17]. The paradoxical feedback activation of the PI3K/Akt pathway may compromise the efficacy of TORC1 inhibitors and provide the rationale for generating dual inhibitors.

Preclinical studies have demonstrated antitumor activity for the PI3K/mTOR inhibitor NVP-BEZ235 (BEZ235) in a variety of models especially those with PI3K mutation or K-Ras mutation $[18,19]$. Here, we examined whether the PI3K/mTOR (both mTORC1 and mTORC2) inhibitors BEZ235 and NVP-BGT226 (BGT226) could sensitise tumor cells with EGFR overexpression or Ras mutation to radiation. We investigated two inhibitors to get a better insight of the efficacy of each compound and test whether comparable results will be obtained. Both dual
PI3K/mTOR inhibitors are issued from the same chemical space (Imidazo-quinolines). BGT226 displays more prolonged effects on target in cells, likely due the slow kinetics on target (high affinity, slow release). Additionally, we studied how PI3K/mTOR inhibition can modify the response of endothelial cells after IR. A substantial body of evidence has demonstrated that the PI3K/mTOR pathway is involved in angiogenesis and functions downstream of vascular endothelial growth factor (VEGF) to promote endothelial cell survival [20-22]. We therefore tested the impact of one the inhibitors, BEZ235, on VEGF-mediated Akt signaling, survival and in vitro angiogenesis in irradiated tumor and endothelial cells.

\section{Methods}

\section{Cell culture}

T24 bladder and FaDu hypopharyngeal cancer cell lines were obtained from ATCC. SQ20B laryngeal squamous cell carcinoma cells were obtained from Dr. Ralph Weichselbaum (University of Chicago, Chicago, IL). Tumor cells were cultured as described [7]. Human umbilical vein endothelial cells (HUVEC) and human dermal microvascular cells (HDMVC) were purchased from Lonza and were maintained in EGM-2 medium (Lonza) supplemented with EGM-2 SingleQuots (Lonza) at $37^{\circ} \mathrm{C}$ in water saturated $5 \% \mathrm{CO} 2 / 95 \%$ air.

\section{Dual PI3K/mTOR inhibitors treatment}

BGT226 and BEZ235 dual PI3K/mTOR inhibitors were obtained from Novartis Pharma AG. The drugs were added to mid-log phase cell cultures. After treatment, medium was replaced with drug-free medium. For the control group, equal amounts of DMSO were used.

\section{Clonogenic survival assay}

The effect of BEZ235 (50 nmol/L) and BGT226 (5 nmol/ L) on tumor cell survival after irradiation was assessed by clonogenic assay, as previously reported [7]. Different drug-radiation schedules were tested (see "Results"). In HUVEC and HDMVC, BEZ235 (50 nmol/L) was added 1 $\mathrm{h}$ before radiation and medium was replaced by basal medium containing $1.5 \%$ FCS and a constant concentration of VEGF $(10 \mathrm{ng} / \mathrm{ml})$ at $1 \mathrm{~h}$ post-irradiation [23].

We also assessed clonogenicity in tumor cells cultured in hypoxia after treatment with one of the PI3K/mTOR inhibitors, BEZ235 (50 nmol/L). For the clonogenic assays performed in hypoxia, tumor cells were incubated in $0.5 \% \mathrm{O} 2$ using an $\mathrm{InVivo}_{2} 300$ chamber (Ruskinn Technology, UK), for $6 \mathrm{~h}$ before irradiation under hypoxic conditions using tightly sealed chambers. The target $\mathrm{O}_{2}$ level was achieved within $6 \mathrm{~h}$ of gassing and maintained during irradiation, as confirmed by an OxyLite oxygen probe (Oxford Optronix). Tumor cells 
irradiated under hypoxia were exposed to normoxia at 1 $\mathrm{h}$ post-irradiation. As standard, BEZ235 was added $1 \mathrm{~h}$ prior to irradiation and was washed away $17 \mathrm{~h}$ after irradiation.

\section{Analysis of protein phosphorylation}

Immunoblotting was performed as described elsewhere [7]. Blocking was performed by $5 \%$ bovine serum albumin for phospho-specific antibodies. Phospho-mTOR (ser-2448), phospho-Akt (ser-473) and phospho-S6 (ser235/236) primary antibodies (Cell Signaling) were used at 1:1,000 dilution. $\beta$-actin clone AC-15 (Sigma) was used at 1:4,000 dilution. Antibody binding was detected with enhanced chemiluminescence kit (GE-Amersham).

\section{Analysis of $\gamma \mathrm{H} 2 \mathrm{AX}$ foci}

Residual DNA damage in irradiated FaDu and SQ20B cells was assessed by measuring residual $\gamma \mathrm{H} 2 \mathrm{AX}$ foci. Cells were pretreated with either BGT226 $(5 \mathrm{nmol} / \mathrm{L})$ or BEZ235 (50 nmol/L) for $1 \mathrm{~h}$ before radiation (4 Gy) and the number of residual foci was determined at 24 hpostirradiation as previously described [7]. Cells were exposed to $\mathrm{PI} 3 \mathrm{~K} / \mathrm{mTOR}$ inhibitor for up to $24 \mathrm{~h}$ postirradiation. Cells were also treated separately with the BEZ235 (50 nmol/L) and radiation (4 Gy), as above, and a time-course analysis of residual $\gamma \mathrm{H} 2 \mathrm{AX}$ foci was performed at 6, 24 and $48 \mathrm{~h}$ post-irradiation.

The number of residual DNA damage foci was also measured in HUVEC at $24 \mathrm{~h}$ post-irradiation (4 Gy). HUVEC were pretreated with BEZ235 $(50 \mathrm{nmol} / \mathrm{L})$ for 1 $\mathrm{h}$ before irradiation. Following irradiation, medium was replaced by basal medium containing $1.5 \%$ FCS and 10 ng/ml VEGF.

\section{Cell cycle assay}

FaDu, SQ20B and HUVEC cells were plated into T25 tissue culture flasks (Falcon) and incubated overnight to allow cells to reach mid-log phase. Tumor cells were treated with BEZ235 ( $50 \mathrm{nmol} / \mathrm{L})$ for $1 \mathrm{~h}$ before irradiation and medium was replaced $17 \mathrm{~h}$ post-irradiation. HUVEC cells were plated in growth-factor depleted medium overnight. Cells were treated with BEZ235 (50 $\mathrm{nmol} / \mathrm{L}$ ) $1 \mathrm{~h}$ before irradiation with a single dose of 4 Gy. Following irradiation, HUVEC medium was replaced by basal medium containing 1.5\% FCS and a constant concentration of VEGF $(10 \mathrm{ng} / \mathrm{ml})$. All cells were trypsinized using 0.5\% Trypsin/EDTA (Life TechnologiesBethesda Research Laboratories) and centrifuged at 1200 rpm. Thereafter, they were washed with PBS, resuspended in $1 \mathrm{~mL}$ ice cold $70 \%$ ethanol and centrifuged again at 1,200 rpm for $10 \mathrm{~min}$. Following this, they were incubated with a mixture of $200 \mu \mathrm{g} / \mathrm{mL}$ RNaseA diluted in PBS with $50 \mu \mathrm{g} / \mathrm{mL}$ propidium iodide (PI), for $30 \mathrm{~min}$ at room temperature, in a dark room. Cell cycle was examined $24 \mathrm{~h}$ post-irradiation using a Becton Dickinson FACSort machine with the Modfit LT analysis software. Data are representative of three independent experiments.

\section{Analysis of apoptosis}

FaDu, SQ20B and HUVEC cells were plated into T25 tissue culture flasks (Falcon) and incubated overnight to allow cells to reach mid-log phase. Tumor cells were treated with PI3K/mTOR inhibitor for $1 \mathrm{~h}$ before irradiation. Medium was replaced $17 \mathrm{~h}$ post-irradiation. HUVEC cells were plated in growth-factor depleted medium overnight. Cells were treated with BEZ235 (50 $\mathrm{nmol} / \mathrm{L}) 1 \mathrm{~h}$ before irradiation with a single dose of 4 Gy. In tumor cells, fresh medium was replaced $17 \mathrm{~h}$ post-irradiation. Similarly to the cell cycle assay, following irradiation, HUVEC medium was replaced by basal medium containing $1.5 \%$ FCS and a constant concentration of VEGF $(10 \mathrm{ng} / \mathrm{ml})$. Cells were allowed to grow and were finally trypsinized at 24 and $48 \mathrm{~h}$ post-irradiation. Apoptosis was analyzed by flow cytometry using FITC Annexin V apoptosis detection kit I (BD Pharmingen) in combination with PI staining, according to the manufacturer's instructions. Analysis of the data was conducted with the FlowJo 7.5 analysis software (Tree Star, Oregon Corporation).

\section{Capillary tube formation and endothelial cell migration}

HUVEC and HDMVC in mid-log phase were plated in growth-factor depleted medium overnight and treated with BEZ235 $(50 \mathrm{nmol} / \mathrm{L})$ for $1 \mathrm{~h}$, before irradiation with 4 Gy. Cells were trypsinized immediately after irradiation and plated onto 24-well plates, previously coated with Matrigel (300 $\mu \mathrm{L}$ per well; BD Biosciences), and incubated in basal medium containing 1.5\% FCS and a constant concentration of VEGF $(10 \mathrm{ng} / \mathrm{ml})$. Once tubules began to form in the control group, cells were stained with calcein (BD Biosciences, Germany), according to the manufacturer's instructions. Three randomly selected digital microphotographs (magnification $\times 10$ for HUVEC and $x 4$ for HDMVC) were obtained from each well. The length of capillary-like tubular structures was measured with the ImageJ software and was normalized to the control group. Experiments were performed twice in quadruplicates.

For the migration assay, cells were trypsinized immediately after irradiation and plated onto the top chamber of 24-well plates (60,000 HUVEC and 30,000 HDMVC/well) with $8 \mu \mathrm{m}$ matrigel-coated inserts (BD Biosciences). Basal medium $(500 \mu \mathrm{L})$ containing $1.5 \%$ FCS and a constant concentration of VEGF $(10 \mathrm{ng} / \mathrm{ml})$ was added to the lower compartment, and cells were incubated for $18 \mathrm{~h}$ and allowed to migrate towards the VEGF-containing medium, according to the manufacturer's instructions. 
Cells were finally scraped off at the upper side of the membrane with a cotton swab and migrated cells were stained with calcein fluorescent dye (BD Biosciences). Three randomly selected digital microphotographs were obtained from each well. The number of migrated endothelial cells (lower side of the membrane) per field (magnification $\times 10$ ) was counted by microscopy. The results represent the mean number of migrated cells, normalized to the control group, as calculated from 3 random fields in quadruplicates.

\section{Statistical analyses}

The values were expressed as means \pm SD. The significance of differences between the means was measured by two-tailed $t$-test or one-way ANOVA using the GraphPad Prism program version 4.0 (GraphPad Software, USA). A value $p<0.05$ was considered statistically significant.

\section{Results}

BGT226 and BEZ235 inhibit PI3K and mTOR activity and reduce AKT and S-6 phosphorylation

We initially aimed to confirm inhibition of PI3K and mTOR by these novel compounds and to establish their minimum inhibitory concentrations. To this end, we analysed the phosphorylation of PI3K pathway downstream targets by Western blotting after treatment of SQ20B cells with BGT226 and BEZ235 in increasing concentrations (Figure 1A). BGT226 and BEZ235 were able to inhibit phosphorylation of Ser473 Akt, Ser2448 mTOR, and Ser240/244 S6 in SQ20B cells at concentrations of $5 \mathrm{nmol} / \mathrm{L}$ and $50 \mathrm{nmol} / \mathrm{L}$, respectively (Figure 1A). BEZ235 (50 nmol/L) inhibited phosphorylation of all three targets within $1 \mathrm{~h}$ of exposure. Inhibition persisted for at least $24 \mathrm{~h}$. Inhibition of pAKT by BGT226 $(5 \mathrm{nmol} / \mathrm{L})$ was relieved after $16 \mathrm{~h}$ (Figure 1B). Signalling inhibition occurred in irradiated cells as well (Figure $1 \mathrm{C}$ and 1D).

The dual PI3K/mTOR inhibitors reduce radiation survival of tumor cells with EGFR overexpression or Ras mutation SQ20B and FaDu are derived from head and neck cancers with overexpression of EGFR. T24 is a bladder cancer cell line with mutated $\mathrm{H}$-Ras. We conducted experiments in order to assess the optimal drug incubation time for colony forming assays with BEZ235 (50 $\mathrm{nmol} / \mathrm{L})$ and BGT226 (5 nmol/L) in SQ20B,T24 and $\mathrm{FaDu}$ cells in the absence of radiation. Exposure of cells to the drugs for $18 \mathrm{~h}$ did not alter plating efficiency (PE) significantly (Figure 1E). Therefore, for subsequent clonogenic assays, cells were pretreated with either compound for $1 \mathrm{~h}$ before irradiation and total incubation time was limited to $18 \mathrm{~h}$. BGT226 and BEZ235 treatment for $18 \mathrm{~h}$ resulted in significant reduction in clonogenic survival after irradiation in all three cell lines (Figure 1F). To quantify the effect, the radiation dose required to reduce the surviving fraction to $10 \%$ was calculated (dose modifying factor $10 \%$; DMF10). The ratio of DMF10 in control cells to BGT226-treated cells was calculated to be 2.6 for SQ20B, 1.6 for FaDu and 1.7 for T24. In BEZ235-treated cells, the DMF10 was 2.5 for SQ20B, 1.5 for FaDu and 1.7 for T24. Thus, there is significant radiosensitisation of these three cell lines by these inhibitors.

To understand the mechanisms of radiosensitisation, we investigated BGT226- and BEZ235-induced enhancement of radiation response in the post-irradiation setting. BGT226 $(5 \mathrm{nmol} / \mathrm{L})$ or BEZ235 $(50 \mathrm{nmol} / \mathrm{L})$ were added to the culture medium of SQ20 and T24 cells immediately or $6 \mathrm{~h}$ after exposure to radiation, for a total exposure time of $18 \mathrm{~h}$. Treatment with drug immediately after irradiation was similar to giving the drug before (Additional file 1: Figure S1A) but if given $6 \mathrm{~h}$ after exposure, no radiosensitizing effect was observed (Additional file 1: Figure S1B). The latter indicates that blockade of the PI3K/mTOR pathway early before or after irradiation is necessary for sensitizing tumor cells to radiation damage.

\section{BEZ235 radiosensitises tumor cells under hypoxic conditions}

Because hypoxic cells can be up to three fold more radioresistant than normoxic cells [1], we asked whether the radiosensitising effect of BEZ235 can still be seen under hypoxic conditions (Additional file 2: Figure S2A-B). Tumor cells were treated with one of the inhibitors, BEZ235 (50 nmol/L) for $1 \mathrm{~h}$ before up to $17 \mathrm{~h}$ after irradiation under hypoxic conditions ( $0.5 \%$ oxygen). Treatment with BEZ235 in the absence of irradiation did not result in significant toxicity in hypoxia (data not shown). Addition of BEZ235 reduced post-irradiation survival significantly for all three cell lines in hypoxia (Additional file 2: Figure S2A). All cell lines showed increased radioresistance under hypoxic conditions, as compared to normoxia, confirming the hypoxic effect in our experimental settings (Additional file 2: Figure S2B). These results show that $\mathrm{PI} 3 \mathrm{~K} / \mathrm{mTOR}$ inhibition can radiosensitise tumor cells in normoxic as well as hypoxic conditions.

\section{BEZ235 induces apoptosis in SQ20B cells and increases necrosis}

We analysed apoptosis in FaDu and SQ20B cells upon administration of BEZ235 (50 nmol/L), in combination with irradiation (4 Gy) (Figure 2A-B). We did not observe any increase in apoptosis in FaDu cells after treatment with BEZ235 alone at either time point while necrosis was increased, especially at $48 \mathrm{~h}$ post-irradiation. In contrast, BEZ235 increased both apoptosis and 


\section{A}
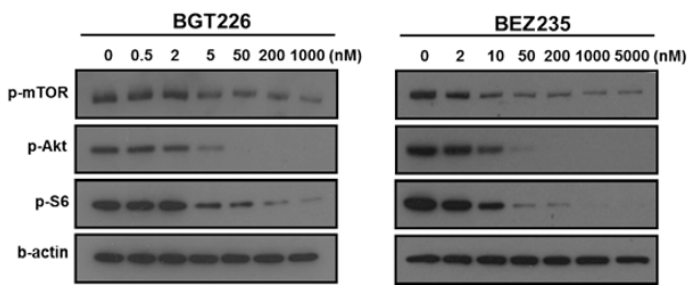

C

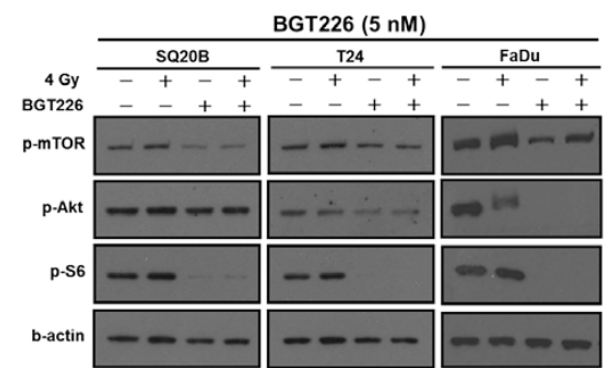

B
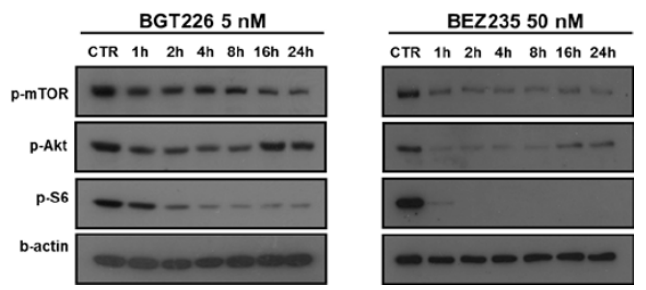

D

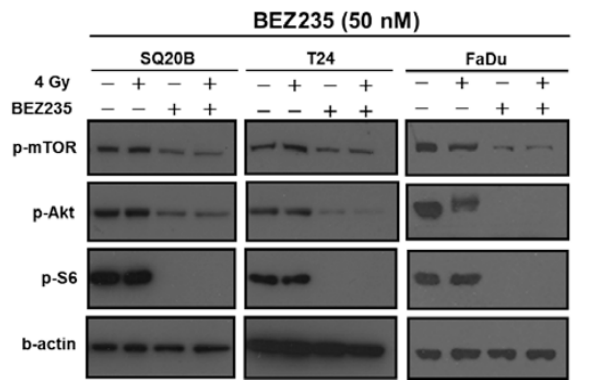

E

\begin{tabular}{|c|c|c|}
\hline \multicolumn{3}{|c|}{ Plating efficiency } \\
\hline Cell line & $\begin{array}{l}\text { Concentration } \\
\text { of the compounds }\end{array}$ & $\begin{array}{l}\text { Mean plating } \\
\text { efficiency (\%) }\end{array}$ \\
\hline \multirow[t]{3}{*}{ SQ20B } & DMSO & $49.8 \%$ \\
\hline & BEZ235 50nM & $43.0 \%$ \\
\hline & BGT226 $5 \mathrm{nM}$ & $47.1 \%$ \\
\hline \multirow[t]{3}{*}{ T24 } & DMSO & $48.0 \%$ \\
\hline & BEZ235 50nM & $45.9 \%$ \\
\hline & BGT226 $5 \mathrm{nM}$ & $52.2 \%$ \\
\hline \multirow[t]{3}{*}{ FaDu } & DMSO & $40.1 \%$ \\
\hline & BEZ235 50nM & $36.8 \%$ \\
\hline & BGT226 $5 \mathrm{nM}$ & $37.1 \%$ \\
\hline
\end{tabular}

$\mathbf{F}$
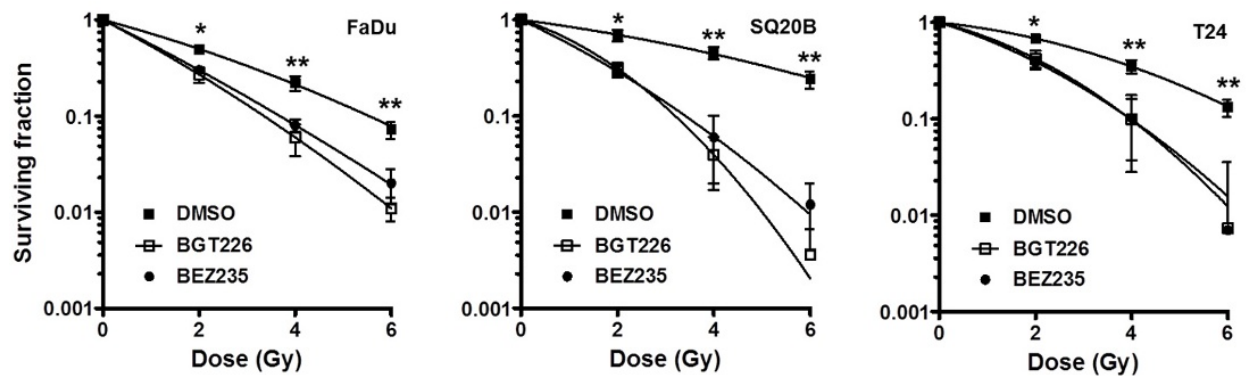

Figure 1 BGT226 and BEZ235 attenuate oncogenic signaling and reduce clonogenic survival after radiation. SQ20B cells were exposed to the indicated drugs for $1 \mathrm{~h}$ and evaluated by Western blotting for phosphorylation of mTOR (Ser2448), Akt (Ser-473) and S6 protein (ser-235/ 236). $\beta$-actin was used as a loading control. $\boldsymbol{A}$, Dose response of the PI3K/mTOR pathway in SQ20B cells after $1 \mathrm{~h}$ exposure to the indicated drug. $\boldsymbol{B}$, Time-course of PI3K/mTOR inhibition to indicated drugs at maximal effective doses. $\boldsymbol{C}-\boldsymbol{D}$, Response of PI3K/mTOR pathway $1 \mathrm{~h}$ after 4 Gy. Cells were treated with $5 \mathrm{nmol} / \mathrm{L}$ BGT226 (C) or $50 \mathrm{nmol} / \mathrm{L}$ BEZ235 (D) for $1 \mathrm{~h}$ before and $1 \mathrm{~h}$ after irradiation. $\boldsymbol{E}$, Plating efficiency of SQ20B, T24 and FaDu cells after exposure to indicated drugs for $1 \mathrm{~h}$ before up to $17 \mathrm{~h}$ post-irradiation $(\mathrm{n}=3)$. $\boldsymbol{F}$, Clonogenic survival of indicated cell lines after $18 \mathrm{~h}$ treatment with BEZ235 (50 nmol/L) and BGT226 (5 nmol/L), as described in "Methods" $(\mathrm{n}=3)$. $\mathrm{P}<0.05$; **, $\mathrm{P}<0.01$ over DMSOtreated control. 


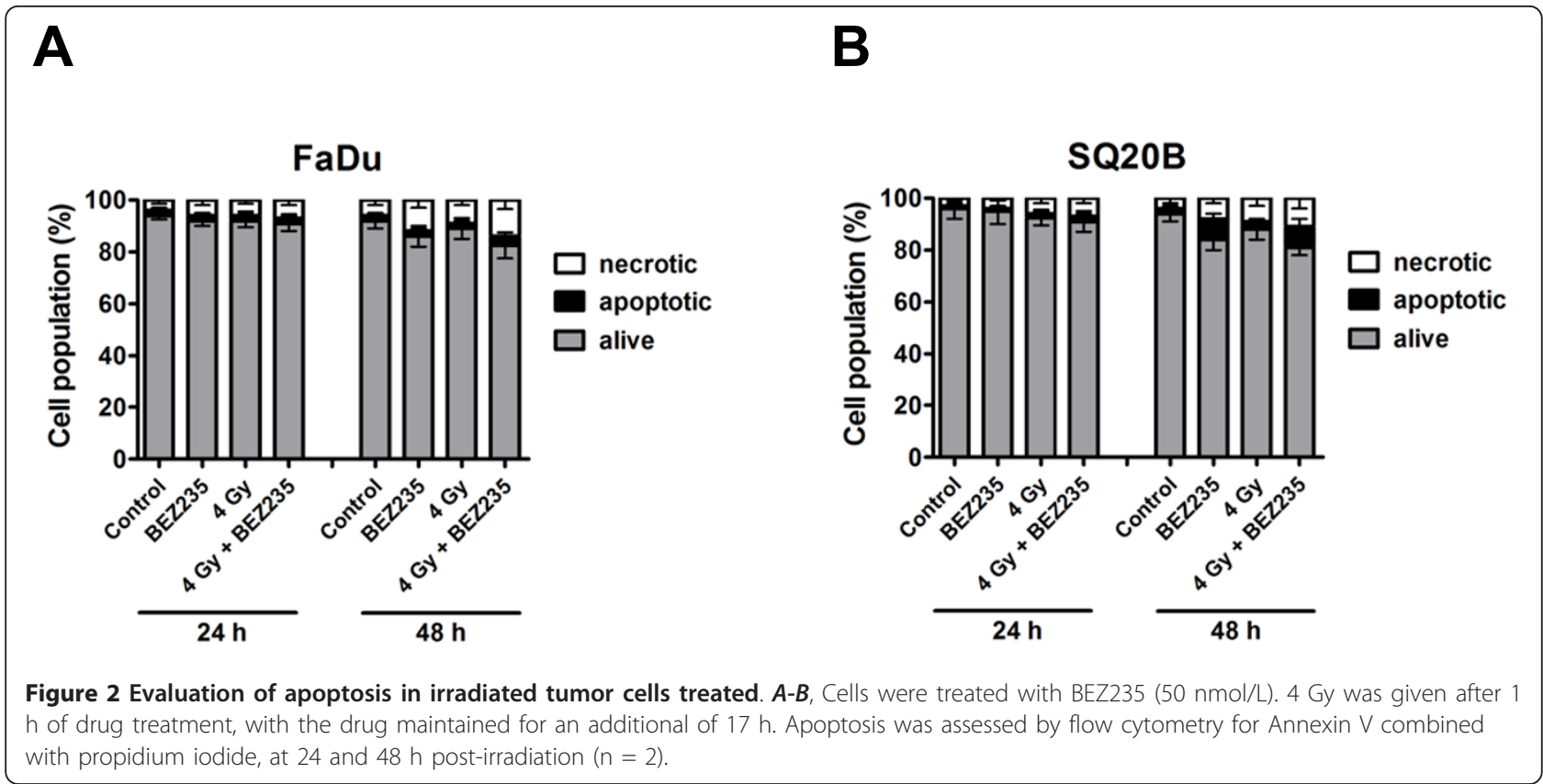

necrosis at $48 \mathrm{~h}$ after irradiation in SQ20B cells. Radiation alone enhanced necrosis at $48 \mathrm{~h}$ post-irradiation in FaDu and SQ20B cells. (Figure 2A-B). The addition of BEZ235 to radiation did not increase apoptosis in either cell line. Only a slight increase in necrosis was observed at $48 \mathrm{~h}$ post-irradiation in both cell lines.

\section{Radiosensitisation induced by the dual PI3K/mTOR inhibitors is accompanied by persistence of $\gamma \mathrm{H} 2 \mathrm{AX}$ foci and cell cycle arrest}

To gain insight into the molecular mechanisms of radiosensitization of both compounds, we investigated the effect of these drugs on the DNA damage response by measuring the number of $\gamma \mathrm{H} 2 \mathrm{AX}$ foci at different time points post-irradiation (4 Gy). A higher number of residual $\gamma \mathrm{H} 2 \mathrm{AX}$ foci was detected after treatment with BGT226 (5 nmol/L) and BEZ235 (50 nmol/L) as compared with radiation alone, at $24 \mathrm{~h}$ post-irradiation (Figure $3 \mathrm{~A}-\mathrm{B})$. We confirmed the higher number of foci after treatment of cells with BEZ235 at different time points post-irradiation in tumor cells (Additional file 3: Figure S3A-B). Although the number of foci decreases more rapidly in $\mathrm{FaDu}$ after radiation alone, the trend at 12, 24 and $48 \mathrm{~h}$ is similar for both FaDu and SQ20B cells and reveals approximately twice as many foci in the combination group, as compared to radiation alone.

We also investigated the impact of $\mathrm{PI} 3 \mathrm{~K} / \mathrm{mTOR}$ inhibition on cell cycle distribution. Treatment with BEZ235 ( $50 \mathrm{nmol} / \mathrm{L}$ ) for $1 \mathrm{~h}$ before irradiation up to $17 \mathrm{~h}$ after led to an increased percentage of cells in G1 phase while $\mathrm{S}$ decreased, indicating a G1 block. Irradiation of FaDu cells led to a G2 block that was substantially increased after treatment with the inhibitor (Figure 3C). Similar effects were obtained from SQ20B cells even though the increase in G2 phase delay in the combination group was less dramatic (Figure 3D). The profound G2 block observed in the combination group underlines the radiosensitizing potential of these drugs.

\section{BEZ235 blocks PI3K/mTOR signaling and sensitizes endothelial cells to irradiation}

Next we wanted to investigate the effect the dual PI3K/ mTOR inhibitors in endothelial cells. To this end, we determined the effect of irradiation and VEGF on the PI3K signalling pathway in HUVEC using BEZ235 (50 $\mathrm{nmol} / \mathrm{L}$ ). In endothelial (HUVEC) cells, Akt was phosphorylated $1 \mathrm{~h}$ after irradiation (4 Gy) or exposure to VEGF-containing medium (10 ng/mL) (Figure 4A; +VEGF). HUVEC exposed to growth factor-depleted medium did not show Akt phosphorylation (Figure 4A; -VEGF). Pre-treatment of HUVEC with BEZ235 led to complete abrogation of $\mathrm{PI} 3 \mathrm{~K} / \mathrm{Akt} / \mathrm{mTOR}$ signalling, in irradiated and unirradiated HUVEC (Figure 4A). Treatment of HUVEC cells with BEZ235 (50 nmol/L) for $1 \mathrm{~h}$ before up to $1 \mathrm{~h}$ after irradiation significantly reduced clonogenic survival in HUVEC (Figure 4B). A similar decrease in clonogenicity was observed in HDMVC, cells that more closely resemble tumor microvascular cells (Figure 4B).

BEZ235 increases DNA damage and necrosis in irradiated endothelial cells

We analysed DNA damage in irradiated cells pretreated with BEZ235 (50 nmol/L) in response to VEGF (10 ng/ 


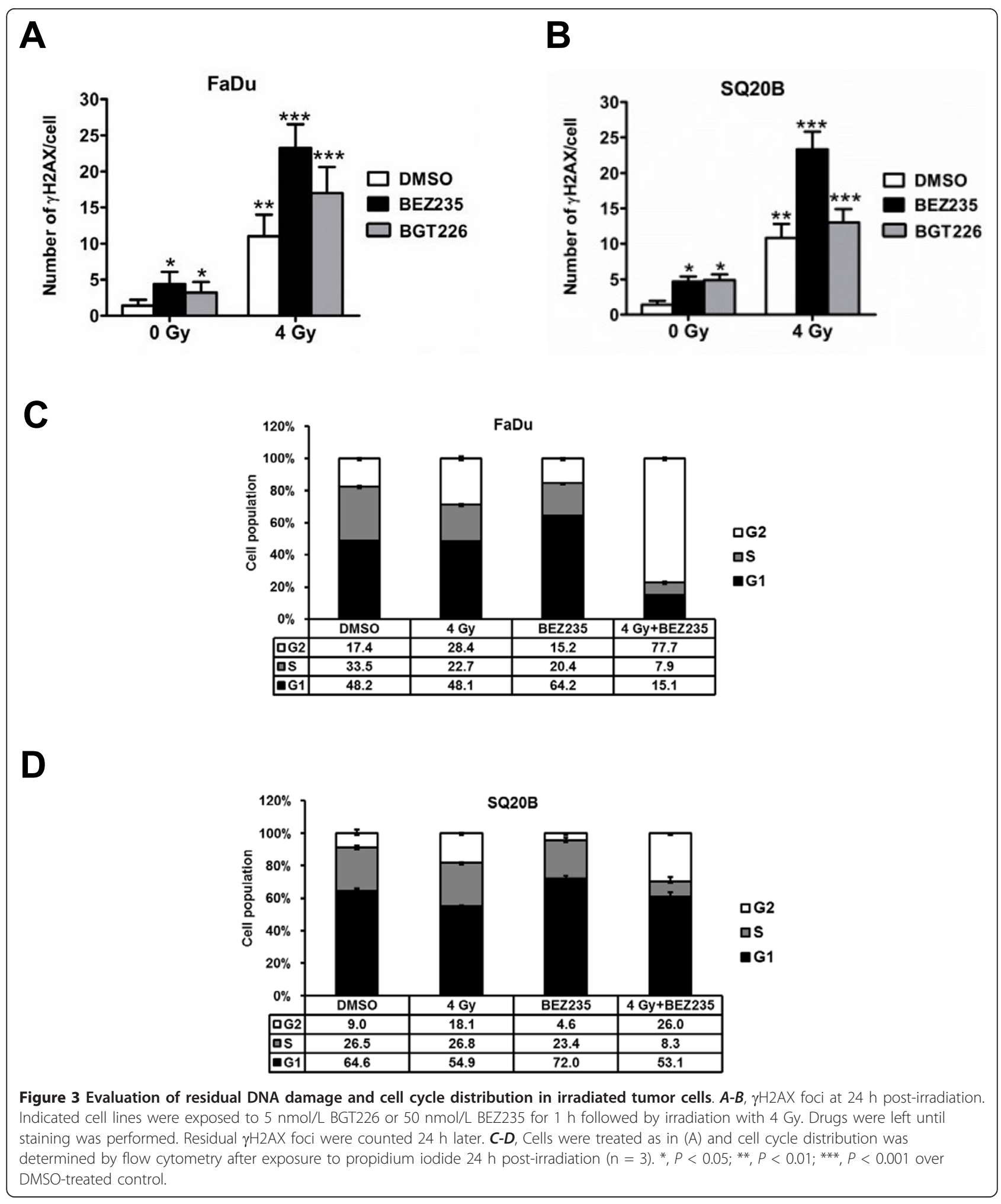

$\mathrm{mL}$ ), as described in Materials and Methods. BEZ235 resulted in enhanced persistence of $\gamma \mathrm{H} 2 \mathrm{AX}$ foci $24 \mathrm{~h}$ after exposure to 4 Gy irradiation (Figure 5A). In addition, BEZ235 treatment only slightly increased apoptosis and necrosis at 24 and $48 \mathrm{~h}$ and enhanced radiationinduced necrosis, especially at $24 \mathrm{~h}$ post-irradiation (Figure 5B). Radiation alone increased necrosis $48 \mathrm{~h}$ after radiation. (Figure 5B). 


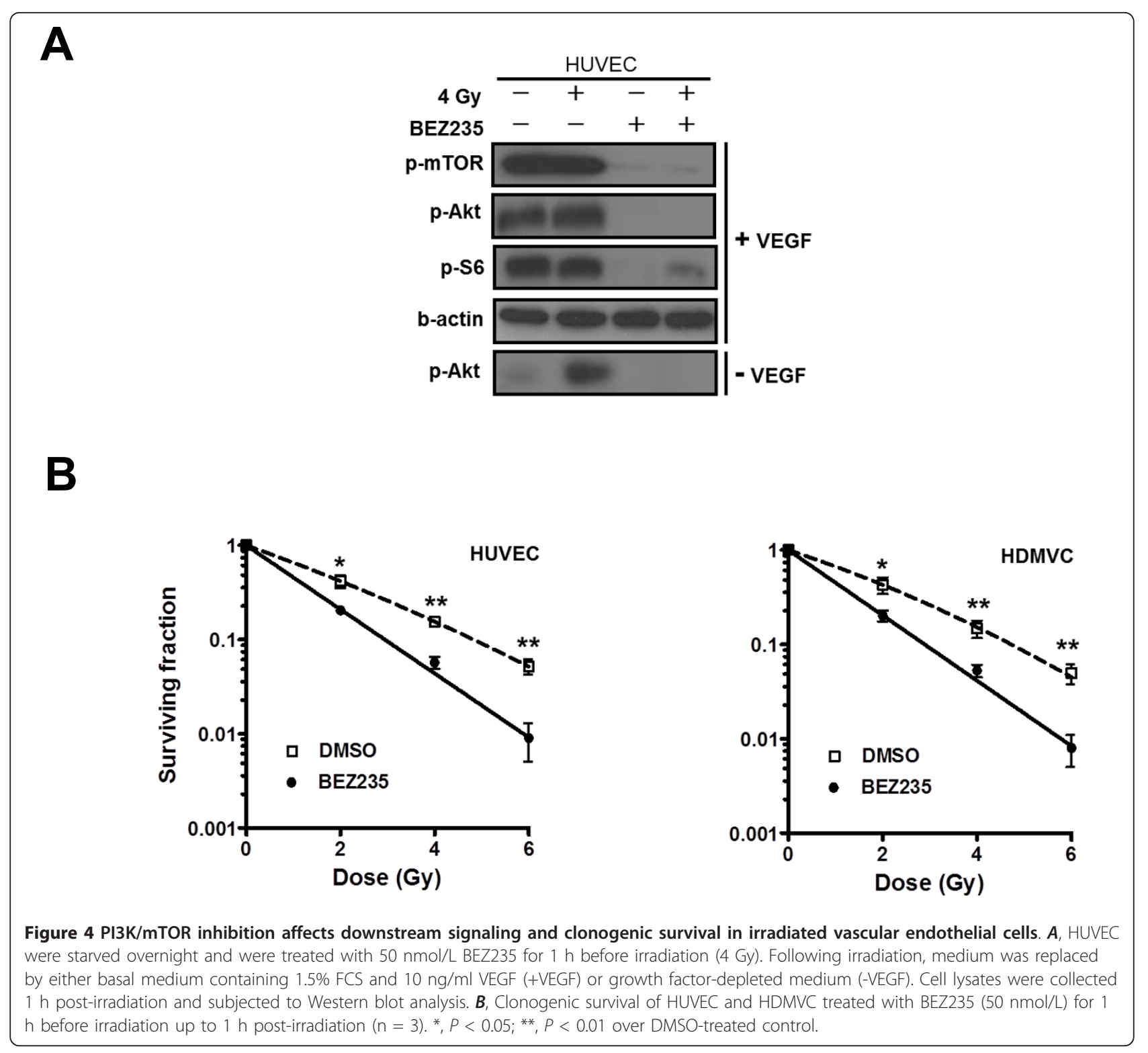

BEZ235 attenuates tube formation and migration in irradiated endothelial cells

To determine whether Akt/mTOR inhibition affects the formation of vascular networks by endothelial cells, a tube formation assay was performed as described in Materials and Methods. BEZ235 (50 nmol/L) or irradiation alone (4 Gy) decreased tube formation in both HUVEC and HDMVC and resulted in shorter tubular structures with fewer interconnection branching points (Figure 6A-B). The combination of BEZ235 with irradiation further potentiated the reduction (Figure 6A-B).

For the migration assay, cells were treated in a similar way as in the tube formation assay and were allowed to migrate to the lower compartment of a transwell chamber. BEZ235 (50 nmol/L) and irradiation (4 Gy) significantly reduced migration of HUVEC and HDMVC (Figure 6CD). Addition of BEZ235 to radiation revealed inhibition of endothelial cells migration (Figure 6C-D). Therefore, dual $\mathrm{PI} 3 \mathrm{~K} / \mathrm{mTOR}$ inhibition can enhance the antivascular effect of radiation in culture.

\section{Discussion}

Our past work and that of others point to increased $\mathrm{PI} 3 \mathrm{~K} / \mathrm{Akt} / \mathrm{mTOR}$ signalling as a mediator of enhanced tumor survival after radiation-induced DNA damage $[3,7,9,24]$. Deregulation of mTOR signalling has also been implicated in response to radiation [14]. Rapalogs have antiproliferative effects in vitro but their efficacy in tumors with PI3K/Akt and mTOR activation has been limited. There is extensive crosstalk between the two 


\section{A}

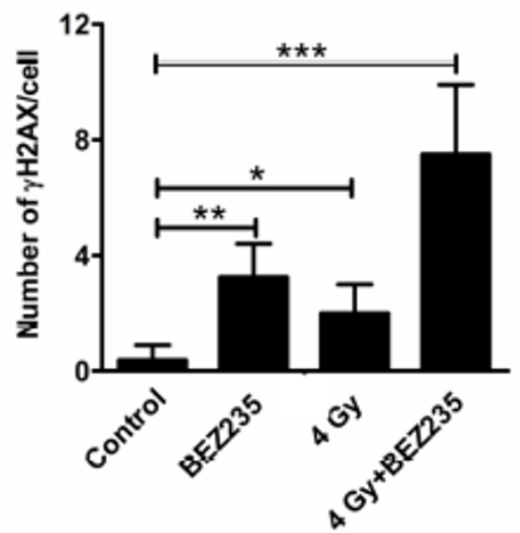

B

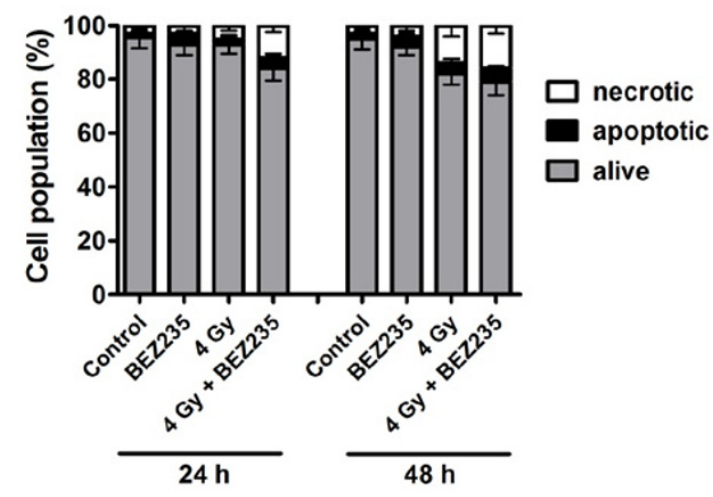

Figure $5 \mathrm{PI3K} / \mathrm{mTOR}$ inhibition enhances DNA damage in irradiated HUVEC. $\boldsymbol{A}$, apoptosis assessment in HUVEC treated with BEZ235 and/or radiation. Previously starved HUVEC were treated with BEZ235 $(50 \mathrm{nmol} / \mathrm{L})$ for $1 \mathrm{~h}$ before irradiation. The medium was removed immediately following irradiation and was replaced by basal medium containing 1.5\% FCS and a constant concentration of VEGF (10 ng/ml).. Annexin V-propidium iodide flow cytometry was used to identify cells in apoptosis or necrosis $72 \mathrm{~h}$ after irradiation. $\boldsymbol{B}$, mean $\gamma \mathrm{H} 2 \mathrm{AX}$ foci number in HUVEC cells treated with BEZ235 (as above) and radiation at $24 \mathrm{~h}$ post-irradiation $(\mathrm{n}=3) .{ }^{*}, P<0.05 ;{ }^{* *}, P<0.01 ;{ }^{* * *}, P<0.001$ over DMSOtreated control.

signalling networks [14,17]. mTOR can affect PI3K/Akt signalling through the S6K-IRS1 feedback loop and induce Akt phosphorylation by mTORC2 [14,25]. Because rapalogs inhibit only the mTORC1 complex, paradoxical activation of Akt can limit their therapeutic potential. Here we have shown that PI3K/mTOR dual inhibitors effectively block downstream targets and result in radiation sensitization in tumor cell lines and in endothelial cells. Interestingly, PI3K/mTOR inhibition resulted in decreased clonogenicity in cells radiated in hypoxia. These data indicate that dual PI3K/mTOR inhibition might prevent PI3K pathway reactivation and further enhance radiation-induced cell killing.

Several preclinical studies have found promising activity for the dual PI3K/mTOR inhibitor BEZ235 against various tumors $[18,19]$ especially those with mutations in PI3K. In the present study, dual inhibitors led to radiosensitization of tumor cells and of endothelium. The efficacy of these compounds should apply to tumor cells with a wide spectrum of oncogenic lesions because the Ras/EGFR/PI3K/mTOR pathway is activated in many types of cancer. Both BGT226 and BEZ235 enhanced the radiosensitivity of SQ20B cells and T24 cells when added before or immediately after radiation but not after $6 \mathrm{~h}$. These findings may support scheduling strategies for future clinical trials testing the radiosensitising potential of these compounds.

To determine whether radiosensitisation was associated with inhibitor-mediated cell cycle redistribution, we analysed cycle distribution in cells pretreated with one of the dual inhibitors, BEZ235. Treatment of FaDu and SQ20B cells with BEZ235 alone resulted in growth arrest in the $G_{1}$ phase.. This is similar to the observation reported in several studies investigating BEZ235 and other PI3K inhibitors [18,26-28]. Importantly, when cells were irradiated after BEZ235 pretreatment, the percentage of $\mathrm{SQ} 20 \mathrm{~B}$ and $\mathrm{FaDu}$ cells in $\mathrm{G} 2$ phase was increased by approximately 3 -fold and 4.5 -fold, respectively. This finding concurs with our previous report on PI3K inhibitor, PI-103 where a $~ 2$-fold increase in G2 phase population arrest was recorded [7]. Notably, rapalogs are known to induce a $G_{2}$ block when combined with irradiation [14].

We also investigated the effect of dual PI3K/mTOR inhibition in apoptosis. BEZ235 increased necrosis but not apoptosis in FaDu cells. In contrast, BEZ235 enhanced both apoptosis and necrosis in SQ20B cells. In the combination group, there was no increased apoptosis in either cell line and only a slight increase in necrosis was observed at $48 \mathrm{~h}$ post-irradiation. Previous studies have demonstrated increased apoptosis after treatment with BEZ235 in some tumor cell lines and lack of apoptosis induction in others. For instance there was no apoptosis induction in glioma or melanoma cell lines $[26,27]$. There is however in lung cancer, sarcoma and leukemia [28-30].

Hypoxic cells are 2 to 3 -fold more resistant than oxic cells to radiation and tumor hypoxia is associated with treatment failure following radical radiotherapy [1]. We were therefore interested to investigate the efficacy of BEZ235 in the context of hypoxia. As expected, hypoxia resulted in increased radioresistance of $\mathrm{FaDu}, \mathrm{SQ} 20 \mathrm{~B}$ 


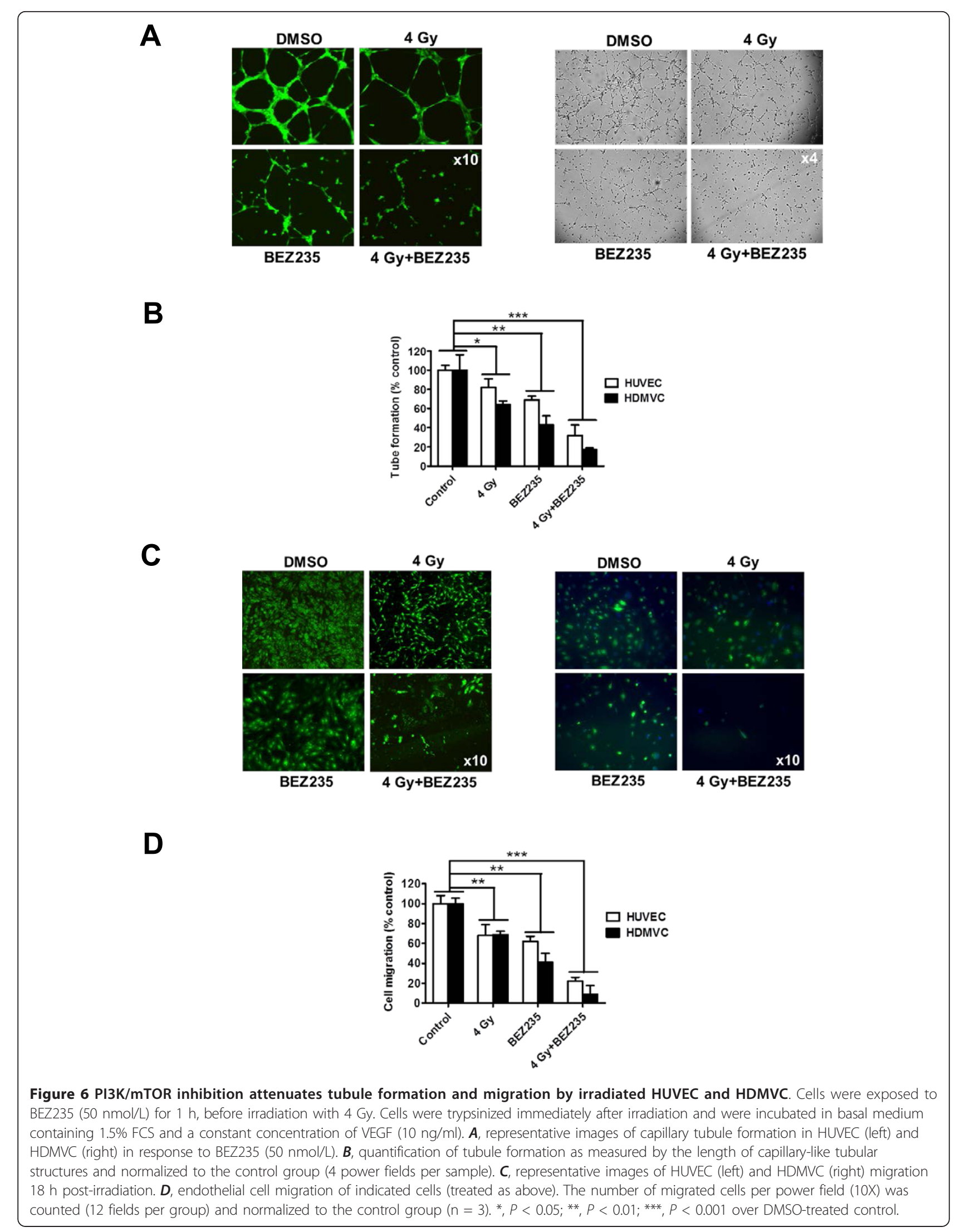


and T24 cells. Importantly, PI3K/mTOR inhibition by BEZ235 led to significant sensitization of hypoxic cells to radiation and therefore this drug can be an attractive adjunct for radiotherapy.

BEZ235 and BGT226 enhanced persistence of residual $\gamma \mathrm{H} 2 \mathrm{AX}$ foci after irradiation. $\gamma \mathrm{H} 2 \mathrm{AX}$ foci were also moderately increased in cells treated with BEZ235 alone, which could be attributed to the potentially toxic effect of the compounds, leading to enhanced DNA damage even in the unirradiated cells. Selective inhibition of the PI3K pathway using siRNA leads to significant radiosensitization of tumor cells. Therefore, the radiosensitizing effect of PI3K/mTOR inhibitors cannot be wholly attributed to inhibition of other targets ("off-target" effect). Previous evidence has demonstrated that inhibition of the PI3K pathway can affect formation of $\gamma \mathrm{H} 2 \mathrm{AX}$ foci, even in the absence of radiation [7]. These indicate that PI3K/ mTOR plays a role in DNA repair after the initial injury. Our results are in accordance to the work of Konstantinidou et al. [29]. Similar findings have been also been described before for different PI3K inhibitors [7,31].

The PI3K/Akt/mTOR intercept node is involved in endothelial signaling response to upstream effectors such as VEGF [22]. Chronic Akt activation in endothelial cells recapitulated the salient features of tumor vasculature [32]. In VEGF-stimulated porcine aortic endothelial cells and HUVEC, VEGFR2 recruited the p110/p85 complex and increased their proliferation [33]. PI3K/Akt/mTOR activation can occur upon exposure to radiation in endothelial cells [22]. Overexpression of Akt in endothelial cells resulted in abnormal vascular remodeling with embryonic lethality [34]. Here BEZ235 blocked VEGF- and irradiation-induced activation of Akt phosphorylation and significantly enhanced cell death in vascular and microvascular endothelial cells. Furthermore, BEZ235 reduced VEGFmediated migration and tube formation and enhanced the antivascular effect of radiation in endothelial cells. We observed a slight increase in apoptosis and necrosis in BEZ235-treated endothelial cells. BEZ235 increased radiation-induced necrosis, especially at $24 \mathrm{~h}$ post-irradiation. Our findings are in accordance with previous reports showing that PI3K and/or mTOR blockade can exert an antivascular activity $[15,22,35]$. The mTOR inhibitor rapamycin decreased VEGF-mediated growth of endothelial cells and activation of Akt/mTOR signaling after irradiation and enhanced the antivascular efficacy of radiotherapy $[15,16,22]$. The fact that dual inhibition of PI3K/mTOR pathway can increase the antivascular effect of radiation in endothelial cells is an important finding. First, PI3K/mTOR inhibition by BEZ235 alone can result in alterations in tumor blood vessel morphology andfunctionality but this appears to be a dose-dependent effect and can affect the efficacy of radiotherapy significantly, as recently demonstrated by our group [36]. Secondly, the enhanced radiosensitization of endothelial cells conferred by BEZ235 would imply that dual PI3K/mTOR inhibition could, in theory, enhance normal tissue damage and therefore special caution is required before proceeding with clinical studies using these agents in combination with radiation.

\section{Conclusions}

In summary, we demonstrated that PI3K/mTOR dual inhibitors are effective radiosensitisers in tumor cells with EGFR overexpression or oncogenic Ras mutation. BEZ235 sensitized tumor cells to radiation under both normoxic and hypoxic conditions. The antivascular activity reported represents a clear advance in understanding the properties of dual PI3K/mTOR inhibition. Altogether, our data indicate that direct inhibition of PI3K/mTOR activity may be of benefit when combined with radiotherapy.

\section{Additional material}

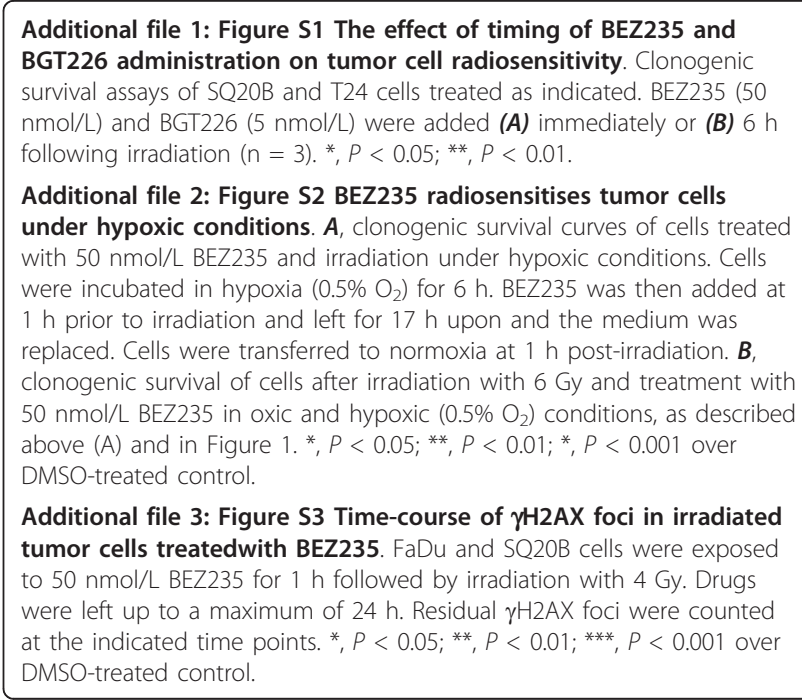

\section{Abbreviations}

PI3K: Phosphatidylinositol 3-kinase; mTOR: Mammalian target of rapamycin; EGFR: Epidermal growth factor receptor; PTEN: Phosphatase and tensin homologue deleted in chromosome 10; VEGF: Vascular endothelial growth factor; HUVEC: Human umbilical vein endothelial cells; HDMVC: Human dermal microvascular cells; DMF10: Dose modifying factor 10\%; PE: Plating efficiency; PI: Propidium iodide.

\section{Acknowledgements}

This work was supported by grants from Cancer Research UK, the Medical Research Council and the NIHR Biomedical Research Centre, Oxford. We would like to thank Michael Woodcock for the technical expertise.

\section{Author details}

${ }^{1}$ Gray Institute for Radiation Oncology and Biology, Oxford University, Oxford, UK. ${ }^{2}$ Novartis Pharma AG, Novartis Campus, CH-4057 Basel, 
Switzerland. ${ }^{3}$ Gray Institute of Radiation Oncology and Biology, University of Oxford, Oxford OX3 7DQ, UK.

\section{Authors' contributions}

$\mathrm{EF}$ and $\mathrm{MY}$ are co-first authors. EF and MY conducted the majority of the experimental procedures. RP and GH participated in the western blots and DNA damage foci analyses. WH and SMM provided the drugs and scientific advice. EB, WGM and RJM conceived the study, and participated in its design and coordination. EM, MY and RJM drafted the manuscript. All authors read and approved the manuscript.

\section{Competing interests}

S-M Maira and W. Hackl are Novartis Pharma employees and shareholders. The other authors disclosed no potential competing interest.

Received: 27 October 2011 Accepted: 27 March 2012 Published: 27 March 2012

\section{References}

1. Begg AC, Stewart FA, Vens C: Strategies to improve radiotherapy with targeted drugs. Nat Rev Cancer 2011, 11:239-253.

2. Maity A, Bernhard EJ: Modulating tumor vasculature through signaling inhibition to improve cytotoxic therapy. Cancer Res 2010, 70:2141-2145.

3. McKenna WG, Muschel RJ, Gupta AK, Hahn SM, Bernhard EJ: The RAS signal transduction pathway and its role in radiation sensitivity. Oncogene 2003, 22:5866-5875.

4. Bernhard EJ, Stanbridge EJ, Gupta S, Gupta AK, Soto D, Bakanauskas VJ, Cerniglia GJ, Muschel RJ, McKenna WG: Direct evidence for the contribution of activated $\mathrm{N}$-ras and $\mathrm{K}$-ras oncogenes to increased intrinsic radiation resistance in human tumor cell lines. Cancer Res 2000, 60:6597-6600

5. Gupta AK, Bakanauskas VJ, Cerniglia GJ, Cheng Y, Bernhard EJ, Muschel RJ, McKenna WG: The Ras radiation resistance pathway. Cancer Res 2001, 61:4278-4282.

6. Kim IA, Fernandes AT, Gupta AK, McKenna WG, Bernhard EJ: The influence of Ras pathway signaling on tumor radiosensitivity. Cancer Metastasis Rev 2004, 23:227-236.

7. Prevo R, Deutsch E, Sampson O, Diplexcito J, Cengel K, Harper J, O'Neill P, McKenna WG, Patel S, Bernhard EJ: Class I PI3 kinase inhibition by the pyridinylfuranopyrimidine inhibitor $\mathrm{PI}-103$ enhances tumor radiosensitivity. Cancer Res 2008, 68:5915-5923.

8. Rudner J, Ruiner CE, Handrick R, Eibl HJ, Belka C, Jendrossek V: The Aktinhibitor Erufosine induces apoptotic cell death in prostate cancer cells and increases the short term effects of ionizing radiation. Radiat Oncol 2010, 5:108.

9. Cengel KA, Voong KR, Chandrasekaran S, Maggiorella L, Brunner TB, Stanbridge E, Kao GD, McKenna WG, Bernhard EJ: Oncogenic K-Ras signals through epidermal growth factor receptor and wild-type H-Ras to promote radiation survival in pancreatic and colorectal carcinoma cells. Neoplasia 2007, 9:341-348.

10. Brunner TB, Cengel KA, Hahn SM, Wu J, Fraker DL, McKenna WG, Bernhard EJ: Pancreatic cancer cell radiation survival and prenyltransferase inhibition: the role of K-Ras. Cancer Res 2005, 65:8433-8441.

11. Li HF, Kim JS, Waldman T: Radiation-induced Akt activation modulates radioresistance in human glioblastoma cells. Radiat Oncol 2009, 4:43.

12. McKenna WG, Muschel RJ, Gupta AK, Hahn SM, Bernhard EJ: Farnesyltransferase inhibitors as radiation sensitizers. Semin Radiat Oncol 2002, 12.27-32

13. Bonner JA, Harari PM, Giralt J, Azarnia N, Shin DM, Cohen RB, Jones CU, Sur R, Raben D, Jassem J, et al: Radiotherapy plus cetuximab for squamous-cell carcinoma of the head and neck. N Engl J Med 2006, 354:567-578.

14. Seeliger H, Guba M, Kleespies A, Jauch KW, Bruns CJ: Role of mTOR in solid tumor systems: a therapeutical target against primary tumor growth, metastases, and angiogenesis. Cancer Metastasis Rev 2007, 26:611-621.

15. Manegold PC, Paringer C, Kulka U, Krimmel K, Eichhorn ME, Wilkowski $R$, Jauch KW, Guba M, Bruns CJ: Antiangiogenic therapy with mammalian target of rapamycin inhibitor RAD001 (Everolimus) increases radiosensitivity in solid cancer. Clin Cancer Res 2008, 14:892-900
16. Shinohara ET, Cao C, Niermann K, Mu Y, Zeng F, Hallahan DE, Lu B: Enhanced radiation damage of tumor vasculature by mTOR inhibitors. Oncogene 2005, 24:5414-5422.

17. Carracedo A, Ma L, Teruya-Feldstein J, Rojo F, Salmena L, Alimonti A, Egia A, Sasaki AT, Thomas G, Kozma SC, et al: Inhibition of mTORC1 leads to MAPK pathway activation through a PI3K-dependent feedback loop in human cancer. J Clin Invest 2008, 118:3065-3074.

18. Maira SM, Stauffer F, Brueggen J, Furet P, Schnell C, Fritsch C, Brachmann S, Chene P, De Pover A, Schoemaker K, et al: Identification and characterization of NVP-BEZ235, a new orally available dual phosphatidylinositol 3-kinase/mammalian target of rapamycin inhibitor with potent in vivo antitumor activity. Mol Cancer Ther 2008, 7:1851-1863.

19. Cho DC, Cohen MB, Panka DJ, Collins M, Ghebremichael M, Atkins MB, Signoretti S, Mier JW: The efficacy of the novel dual PI3-kinase/mTOR inhibitor NVP-BEZ235 compared with rapamycin in renal cell carcinoma. Clin Cancer Res 2010, 16:3628-3638.

20. Reaper PM, Griffiths MR, Long JM, Charrier JD, Maccormick S, Charlton PA, Golec JM, Pollard JR: Selective killing of ATM- or p53-deficient cancer cells through inhibition of ATR. Nat Chem Biol 2011, 7:428-430.

21. Abid MR, Guo S, Minami T, Spokes KC, Ueki K, Skurk C, Walsh K, Aird WC: Vascular endothelial growth factor activates PI3K/Akt/forkhead signaling in endothelial cells. Arterioscler Thromb Vasc Biol 2004, 24:294-300.

22. Kim DW, Huamani J, Fu A, Hallahan DE: Molecular strategies targeting the host component of cancer to enhance tumor response to radiation therapy. Int J Radiat Oncol Biol Phys 2006, 64:38-46.

23. Wood JM, Bold G, Buchdunger E, Cozens R, Ferrari S, Frei J, Hofmann F, Mestan J, Mett H, O'Reilly T, et al: PTK787/ZK 222584, a novel and potent inhibitor of vascular endothelial growth factor receptor tyrosine kinases, impairs vascular endothelial growth factor-induced responses and tumor growth after oral administration. Cancer Res 2000, 60:2178-2189.

24. Pore N, Gupta AK, Cerniglia GJ, Jiang Z, Bernhard EJ, Evans SM, Koch CJ, Hahn SM, Maity A: Nelfinavir down-regulates hypoxia-inducible factor 1alpha and VEGF expression and increases tumor oxygenation: implications for radiotherapy. Cancer Res 2006, 66:9252-9259.

25. Wang X, Yue P, Chan CB, Ye K, Ueda T, Watanabe-Fukunaga R, Fukunaga R, Fu H, Khuri FR, Sun SY: Inhibition of mammalian target of rapamycin induces phosphatidylinositol 3-kinase-dependent and Mnk-mediated eukaryotic translation initiation factor $4 \mathrm{E}$ phosphorylation. Mol Cell Biol 2007, 27:7405-7413.

26. Liu TJ, Koul D, LaFortune T, Tiao N, Shen RJ, Maira SM, Garcia-Echevrria C, Yung WK: NVP-BEZ235, a novel dual phosphatidylinositol 3-kinase/ mammalian target of rapamycin inhibitor, elicits multifaceted antitumor activities in human gliomas. Mol Cancer Ther 2009, 8:2204-2210.

27. Marone R, Erhart D, Mertz AC, Bohnacker T, Schnell C, Cmiljanovic V Stauffer F, Garcia-Echeverria C, Giese B, Maira SM, Wymann MP: Targeting melanoma with dual phosphoinositide 3-kinase/mammalian target of rapamycin inhibitors. Mol Cancer Res 2009, 7:601-613.

28. Manara MC, Nicoletti G, Zambelli D, Ventura S, Guerzoni C, Landuzzi L, Lollini PL, Maira SM, Garcia-Echeverria C, Mercuri M, et al: NVP-BEZ235 as a new therapeutic option for sarcomas. Clin Cancer Res 2010, 16:530-540.

29. Konstantinidou G, Bey EA, Rabellino A, Schuster K, Maira MS, Gazdar AF, Amici A, Boothman DA, Scaglioni PP: Dual phosphoinositide 3-kinase/ mammalian target of rapamycin blockade is an effective radiosensitizing strategy for the treatment of non-small cell lung cancer harboring K-RAS mutations. Cancer Res 2009, 69:7644-7652.

30. Chiarini F, Grimaldi C, Ricci F, Tazzari PL, Evangelisti C, Ognibene A, Battistelli M, Falcieri E, Melchionda F, Pession A, et al: Activity of the novel dual phosphatidylinositol 3-kinase/mammalian target of rapamycin inhibitor NVP-BEZ235 against T-cell acute lymphoblastic leukemia. Cancer Res 2010, 70:8097-8107.

31. Vispe S, Cazaux C, Lesca C, Defais M: Overexpression of Rad51 protein stimulates homologous recombination and increases resistance of mammalian cells to ionizing radiation. Nucleic Acids Res 1998, 26:2859-2864.

32. Phung TL, Ziv K, Dabydeen D, Eyiah-Mensah G, Riveros M, Perruzzi C, Sun J, Monahan-Earley RA, Shiojima I, Nagy JA, et al: Pathological angiogenesis is induced by sustained Akt signaling and inhibited by rapamycin. Cancer Cell 2006, 10:159-170.

33. Dayanir V, Meyer RD, Lashkari K, Rahimi N: Identification of tyrosine residues in vascular endothelial growth factor receptor-2/FLK-1 involved 
in activation of phosphatidylinositol 3-kinase and cell proliferation. J Biol Chem 2001, 276:17686-17692.

34. Sun JF, Phung T, Shiojima I, Felske T, Upalakalin JN, Feng D, Kornaga T, Dor T, Dvorak AM, Walsh K, Benjamin LE: Microvascular patterning is controlled by fine-tuning the Akt signal. Proc Natl Acad Sci USA 2005, 102:128-133.

35. Raynaud FI, Eccles S, Clarke PA, Hayes A, Nutley B, Alix S, Henley A, DiStefano F, Ahmad Z, Guillard S, et al: Pharmacologic characterization of a potent inhibitor of class I phosphatidylinositide 3-kinases. Cancer Res 2007, 67:5840-5850.

36. Fokas E, Im JH, Hill S, Yameen S, Stratford M, Beech J, Hackl W, Maira SM, Bernhard EJ, McKenna WG, Muschel RJ: Dual inhibition of the PI3K/mTOR pathway increases tumor radiosensitivity by normalizing tumor vasculature. Cancer Res 2012, 72:239-248.

doi:10.1186/1748-717X-7-48

Cite this article as: Fokas et al:: NVP-BEZ235 and NVP-BGT226, dual phosphatidylinositol 3-kinase/mammalian target of rapamycin inhibitors, enhance tumor and endothelial cell radiosensitivity. Radiation Oncology 2012 7:48.

\section{Submit your next manuscript to BioMed Central} and take full advantage of:

- Convenient online submission

- Thorough peer review

- No space constraints or color figure charges

- Immediate publication on acceptance

- Inclusion in PubMed, CAS, Scopus and Google Scholar

- Research which is freely available for redistribution

Submit your manuscript at www.biomedcentral.com/submit 